\title{
Withaferin A inhibits matrix metalloproteinase-9 activity by suppressing the Akt signaling pathway
}

\author{
DAE HYUNG LEE ${ }^{2 *}$, IN-HYE LIM ${ }^{1 *}$, EON-GI SUNG ${ }^{1}$, JOO-YOUNG KIM $^{1}$, \\ IN-HWAN SONG ${ }^{1}$, YOON KI PARK ${ }^{2}$ and TAE-JIN LEE ${ }^{1}$ \\ Departments of ${ }^{1}$ Anatomy, College of Medicine, and ${ }^{2}$ Obstetrics and Gynecology, \\ Yeungnam University, Daegu 705-717, Republic of Korea
}

Received February 22, 2013; Accepted April 29, 2013

DOI: $10.3892 /$ or.2013.2487

\begin{abstract}
Withaferin A (Wit A), a steroidal lactone isolated from Withania somnifera, exhibits anti-inflammatory, immunomodulatory and anti-angiogenic properties and antitumor activities. In the present study, we investigated the effects of Wit A on protease-mediated invasiveness of the human metastatic cancer cell lines Caski and SK-Hep1. We found that treatment with Wit A resulted in marked inhibition of the TGF- $\beta$-induced increase in expression and activity of matrix metalloproteinase (MMP)-9 in Caski cell line. These effects of Wit A were dose-dependent and showed a correlation with suppression of MMP-9 mRNA expression levels. Treatment with Wit A resulted in an $\sim 1$.6-fold induction of MMP-9 promoter activity, which was also suppressed by treatment with Wit A in Caski cells. We found that treatment with Wit A resulted in inhibition of TGF- $\beta$-induced phosphorylation of Akt, which was involved in the downregulation of expression of MMP-9 at the protein level. Introduction with constitutively active (CA)-Akt resulted in a partial increase in the secretion of TGF- $\beta$-induced MMP-9 blocked by treatment with Wit A in Caski cells. According to these results, Wit A may inhibit the invasive and migratory abilities of Caski cells through a reduction in MMP-9 expression through suppression of the pAkt signaling pathway. These findings indicate that use of Wit A may be an effective strategy for control of metastasis and invasiveness of tumors.
\end{abstract}

\section{Introduction}

Matrix metalloproteinases (MMPs), zinc- and calciumdependent metalloproteinases are involved in the degradation of the various components of the extracellular matrix (ECM),

Correspondence to: Professor Tae-Jin Lee, Department of Anatomy, College of Medicine, Yeungnam University, 170 Hyeonchung-ro, Nam-gu, Daegu 705-717, Republic of Korea

E-mail: tjlee@med.yu.ac.kr

"Contributed equally

Key words: withaferin A, MMP-9, TGF- $\beta$, Caski, pAkt such as collagen, laminin, fibronectin, vitronectin, elastin and proteoglycans (1). Among the previously reported human MMPs, gelatinase-A (MMP-2) and gelatinase-B (MMP-9) are key enzymes involved in the degradation of type IV collagen, a major component of the basement membrane (2,3). Recent studies have reported a positive correlation between expression of MMP-9 and tumor metastasis in cervical cancer as well as several types of epithelial cancer (4-7); thus, inhibition of MMP activity has been adopted as an anticancer therapeutic strategy.

Withaferin A (Wit A), a bioactive compound isolated from Withania somnifera, is a cell permeable steroidal lactone, and exhibits anti-inflammatory and immunomodulatory activities. Wit A suppresses growth of human cancer cells of the prostate, breast, and soft tissue sarcoma origin in vitro and in vivo (8-10). In addition, Wit $\mathrm{A}$ is a potent inhibitor of angiogenesis in vivo via inhibition of proliferation of HUVECs (11). More recently, Wit A was reported to trigger apoptosis and to inhibit cell migration and invasion of breast cancer cells (12).

Wit $\mathrm{A}$ inhibits the motility and invasiveness of carcinoma cells in vitro, yet the inhibitory mechanism(s) of TGF- $\beta$ induced motility and invasiveness as well as the TGF- $\beta$-induced MMP-9 activation of carcinoma cells by Wit A are not well defined. The aim of this study was to evaluate the inhibitory effect of Wit A on TGF- $\beta$-mediated invasion as well as MMP-9 expression and activity in Caski cells. In addition, we attempted to determine whether inhibition of these MMPs by treatment with Wit A is mediated through cellular signaling pathways, such as by inhibition of the phosphorylation of the Akt pathway in Caski cells.

\section{Materials and methods}

Cells and materials. Human Caski and SK-Hep-1 cells were obtained from the American Type Culture Collection (Rockville, MD, USA). Dulbecco's modified Eagle's medium (DMEM), supplemented with $2 \mathrm{mM}$ L-glutamine, $100 \mathrm{U} / \mathrm{ml}$ penicillin, $100 \mu \mathrm{g} / \mathrm{ml}$ streptomycin, and $10 \%$ fetal bovine serum (FBS) was the culture medium used throughout the experiments. Wit A was purchased from Calbiochem (La Jolla, CA, USA). Lipofectamine 2000 reagent was obtained from Life Technologies, Inc. (Rockville, MA, USA). Luciferase assay and $\beta$-galactosidase assay systems were purchased from Promega (Madison, WI, USA). 
Cell viability assay. The 3-[4,5-dimethylthiazol-2-yl]2,5-diphenyl tetrazolium bromide] (MTT) assay was used for determination of the effect of Wit A on cell viability. Cells were seeded into 96 -well plates at a density of $3 \times 10^{4}$ cells/100 $\mu \mathrm{l} /$ well. After $24 \mathrm{~h}$ of growth, cells were treated with different concentrations of Wit A ranging from 0.8 to $1.2 \mu \mathrm{M}$ for $24 \mathrm{~h}$. After the exposure period, the medium was removed, and the cells were washed with PBS. The medium was then replaced, followed by incubation with the MTT solution (Promega) for $4 \mathrm{~h}$. The number of viable cells was directly proportional to the production of formazan, which was dissolved in DMSO, followed by spectrophotometric measurement at $563 \mathrm{~nm}$. The percentage of viable cells was estimated by comparison with that of the untreated control cells.

Gelatin substrate gel zymography. To determine the effect of Wit A on TGF- $\beta$ - or PMA-induced MMP-9 activity, cells were treated with various concentrations of Wit $A$ in the presence of $50 \mathrm{ng} / \mathrm{ml}$ TGF- $\beta$ or $75 \mathrm{nM}$ PMA, followed by performance of zymography for evaluation of MMP-9 expression. Zymography was performed using the procedure described by Overall et al (13) with minor modifications. The human cell lines were suspended in their respective medium containing $10 \%$ FBS and plated at $8 \times 10^{5}$ cells. Dishes were incubated until reaching $\sim 80 \%$ confluency, and the medium was aspirated, followed by addition of fresh serum-free medium to each dish, with or without Wit A. Supernatants were collected after incubation for $24 \mathrm{~h}$. Supernatants were subjected to SDS-PAGE in $10 \%$ polyacrylamide gels, which were copolymerized with $1 \mathrm{mg} / \mathrm{ml}$ of gelatin. After electrophoresis, the gels were washed several times in $2.5 \%$ Triton $\mathrm{X}-100$ for $1 \mathrm{~h}$ at room temperature for removal of SDS, followed by incubation for $24-48 \mathrm{~h}$ at $37^{\circ} \mathrm{C}$ in buffer containing $5 \mathrm{mM} \mathrm{CaCl}_{2}$ and $1 \mu \mathrm{M}$ $\mathrm{ZnCl}_{2}$. The gels were stained with Coomassie blue $(0.25 \%)$ for $30 \mathrm{~min}$, followed by destaining for $1 \mathrm{~h}$ in a solution of acetic acid and methanol. The proteolytic activity was evidenced as clear bands (zones of gelatin degradation) against the blue background of the stained gelatin.

Plasmids, transfection, and luciferase gene assays. The MMP-9 reporter construct was kindly provided by Dr T.K. Kwon (Keimyung University, School of Medicine, Korea). In brief, cells were plated onto 6-well plates at a density of $5 \times 10^{5}$ cells/well and grown overnight. Cells were transfected with $2 \mu \mathrm{g}$ of the MMP-9 promoter construct and $1 \mu \mathrm{g}$ of the pCMV- $\beta$-galactosidase plasmid for $5 \mathrm{~h}$ using the Lipofectamine 2000 method. After transfection, cells were cultured in $10 \%$ FBS medium with vehicle (DMSO) or drugs for $24 \mathrm{~h}$. Luciferase and $\beta$-galactosidase activities were assayed according to the manufacturer's protocol (Promega). Luciferase activity was normalized for $\beta$-galactosidase activity in cell lysate and expressed as an average of three independent experiments.

RNA isolation and RT-PCR. To determine whether the reduced amounts of MMP-9 activity were a result of decreased levels of mRNA encoding this collagenase, we compared the levels of MMP-9 in several types of cancer cells treated with or without various concentrations of Wit $\mathrm{A}$ in the presence of TGF- $\beta$ or PMA. RT-PCR was performed for determination of
MMP-9 mRNA expression. Total cellular RNA was extracted from Caski cells using TRIzol reagent (Life Technologies, Inc.). cDNA was synthesized from $2 \mu \mathrm{g}$ of total RNA using Moloney murine leukemia virus reverse transcriptase (Life Technologies, Inc.). The sequences of the sense and antisense primers for MMP-9 were 5'-CACTGTCCACCCCTCAGA GC-3' and 5'-GCCACTTGTCGGCGATAAGG-3', respectively. For analysis of PCR products, agarose gel electrophoresis was performed, followed by visualization using ethidium bromide.

Invasion assay. Each invasion assay was performed using $5 \times 10^{4}$ cells/chamber. Invasion assays were performed using modified Boyden chambers with a polycarbonate nucleopore membrane (Corning, Corning, NY, USA). Precoated filters $\left(6.5-\mathrm{mm}\right.$ in diameter, $8-\mu \mathrm{m}$ pore-size, Matrigel $\left.100 \mu \mathrm{g} / \mathrm{cm}^{2}\right)$ were rehydrated with $250 \mu \mathrm{l}$ of medium, and $5 \times 10^{4}$ cells in $200 \mu \mathrm{l}$ medium with or without Wit $\mathrm{A}$ in the presence of TGF- $\beta$ or PMA were seeded into the upper part of each chamber. After incubation for $24 \mathrm{~h}$ at $37^{\circ} \mathrm{C}$, nonmigratory cells on the upper surface of the filter were wiped with a cotton swab and cells that had migrated to the lower surface of the filter were fixed and stained with $0.125 \%$ Coomassie blue in a methanol:acetic acid:water mixture (45:10:45, v/v/v). Random fields were counted under a light microscope.

\section{Results}

Effect of Wit A on the cell viability of Caski cells. We assessed the cell viability of human cervical cancer Caski cells following treatment with various concentrations $(0.8-1.2 \mu \mathrm{M})$ of Wit A. Compared with the controls, the cell viability in Caski cells was not markedly altered following treatment with Wit A, even at a concentration up to $1.2 \mu \mathrm{M}$ (Fig. 1). As shown in Fig. 1B, Wit A did not markedly influence cell viability in Caski cells from 6 to $24 \mathrm{~h}$ following treatment with $1.2 \mu \mathrm{M}$ Wit A. Therefore, it was clear that treatment of Caski cells with Wit A for $24 \mathrm{~h}$, at concentrations ranging from 0.8 to $1.2 \mu \mathrm{M}$, has no cytotoxic effects.

Effect of Wit A on MMP-9 activity. Caski cells, which release basal levels of MMP-9 when cultured in serum-free medium, were treated with TGF- $\beta$ for $24 \mathrm{~h}$. Although the level of MMP-2 expression was not significantly altered by TGF- $\beta$, TGF- $\beta$ induced the expression and secretion of large amounts of latent MMP-9, as determined by gelatin zymography (Fig. 2A). As shown in Fig. 2A, treatment with Wit A resulted in decreased TGF- $\beta$-induced MMP-2 and MMP-9 activities in a dose-dependent manner.

Suppression of TGF- $\beta$-induced MMP-9 transcription by Wit $A$. Treatment of Caski cells with Wit A induced a decrease in the levels of TGF- $\beta$-stimulated MMP-9 mRNA (Fig. 2B). Results of RT-PCR showed that steady-state levels of MMP-9 mRNA were lower in Wit A-treated cells, compared with nontreated cells. The effect of treatment with Wit A on expression of MMP-9 was additionally investigated using Caski cells transiently transfected with a luciferase reporter gene linked to the 0.7-kb fragment of the MMP-9 promoter sequence. Activation of luciferase gene expression up to 1.6-fold was observed 

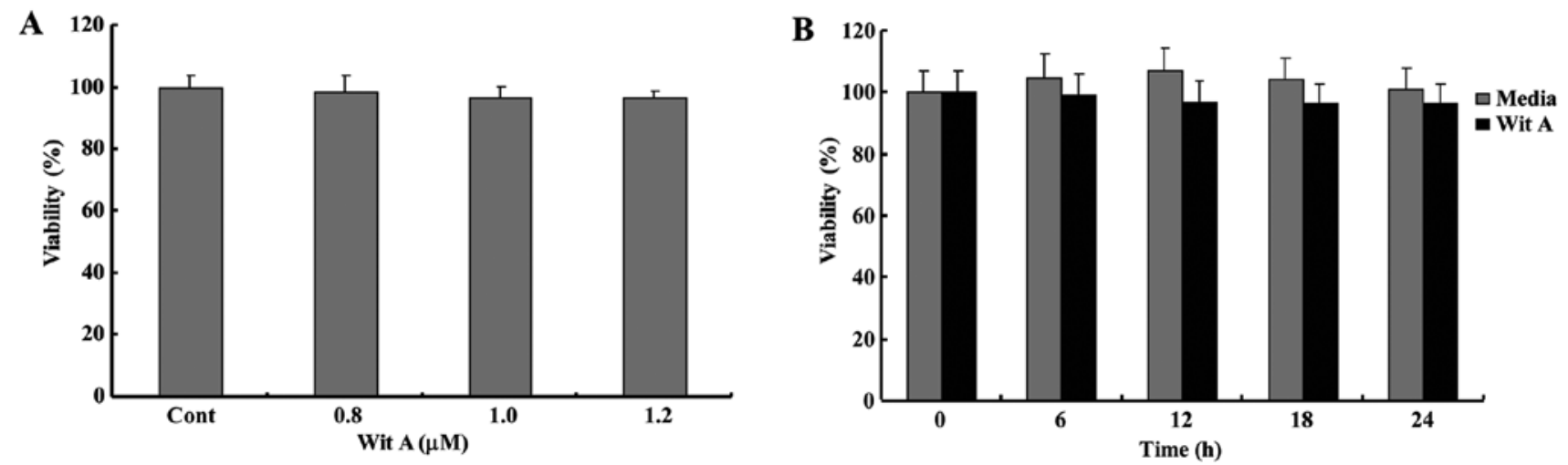

Figure 1. Effects of various concentrations of Wit A on the cell viability of cultured Caski cells. (A) Proliferation of the cells was quantified as the cell survival rate after $24 \mathrm{~h}$ at doses of Wit A ranging from 0.8 to $1.2 \mu \mathrm{M}$ as assessed by MTT assay. Relative cell viability in Wit A-treated cells was expressed as a ratio to values of the control cells. Results are shown as means \pm SE. The bars represent the standard error of the values. (B) Proliferation of the cells was quantified as the cell survival rate after treatment for $6-24 \mathrm{~h}$ at a dose of $1.2 \mu \mathrm{M}$ Wit A.
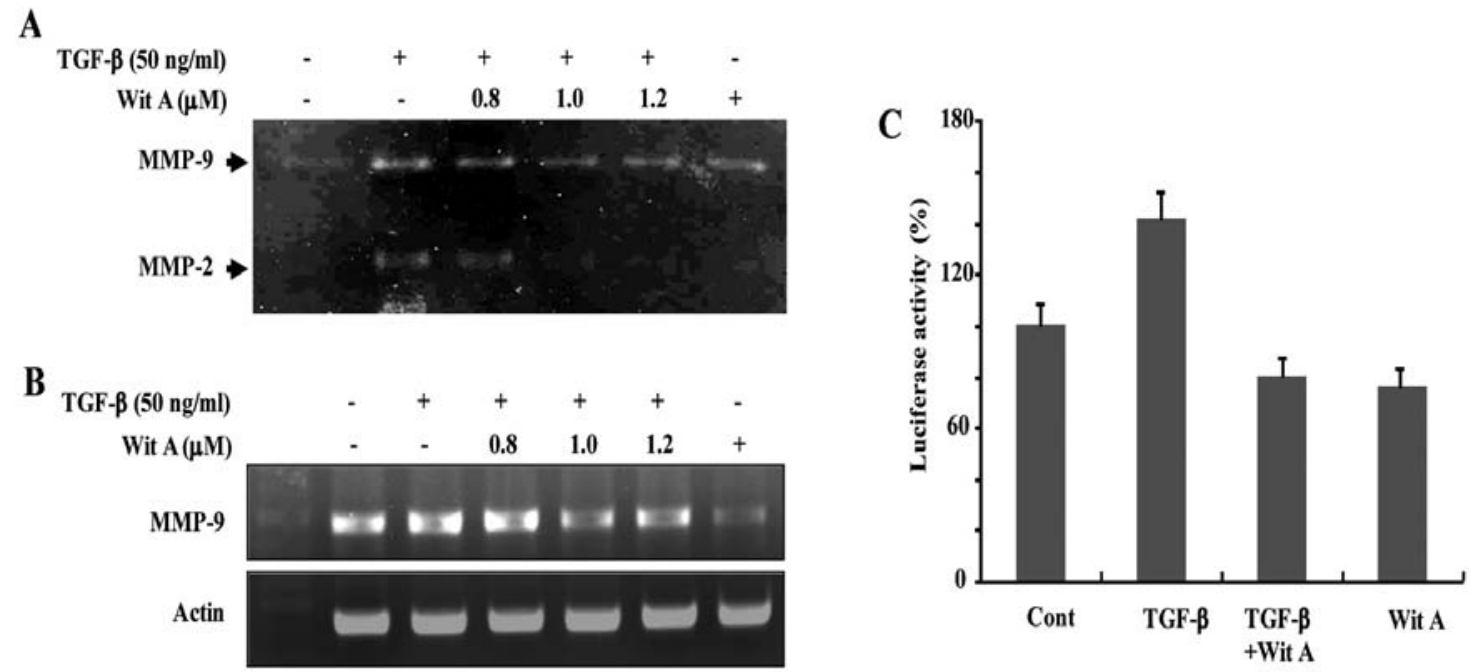

Figure 2. Effect of Wit A on the activity and expression of MMP-9 in Caski cells. (A) Caski cells were treated with various concentrations or without Wit A in the presence of TGF- $\beta(50 \mathrm{ng} / \mathrm{ml})$ for $24 \mathrm{~h}$. The conditioned media were collected and gelatin and casein zymography was performed for determination of MMP-2 and MMP-9 activities. (B) Caski cells were treated with various concentrations or without Wit A in the presence of TGF- $\beta$ (50 ng/ml) for $24 \mathrm{~h}$. Total RNA was isolated, and RT-PCR analysis was performed. The MMP-9 mRNA levels shown are representative of three independent experiments. (C) Caski cells were transfected with the WT-MMP-9 promoter-containing reporter vector and treated with various concentrations of Wit A in the absence or presence of TGF- $\beta(50 \mathrm{ng} / \mathrm{ml})$. The cells were lysed, and the luciferase activity was measured. Results are shown as means \pm SE. The bars represent the standard error of the values.

in cells treated with TGF- $\beta$, compared with untreated cells. Treatment of cells with Wit $\mathrm{A}(1.2 \mu \mathrm{M})$ resulted in a decrease in TGF- $\beta$-mediated luciferase activity (Fig. $2 \mathrm{C}$ ).

Effects of Wit A on migration of Caski cells. We next examined the effect of Wit A on migration of Caski cells using the cell invasion assay. As shown in Fig. 3, treatment with $1.2 \mu \mathrm{M}$ Wit A resulted in a significant reduction in TGF- $\beta$-induced invasiveness of these cells by $\sim 44 \%$, compared with the TGF- $\beta$-treated cells, although reduced invasion was still observed in the presence of Wit A. Therefore, the effect of Wit A on in vitro invasion inhibition showed a correlation with its effect on MMP-9 inhibition.

Wit A inhibits TGF- $\beta$-induced secretion of MMP-9 and phosphorylation of Akt in Caski cells. Treatment of Caski cells with TGF- $\beta$ also resulted in an increase in the levels of phosphorylation of Akt, compared with the control, which was markedly attenuated by treatment with Wit A. In order to determine whether the decrease in TGF- $\beta$-induced invasiveness of the cells following treatment with Wit A was related to the Akt signaling pathway, Caski cells were transiently transfected with an empty vector and constitutively active (CA)-Akt expression vector. As shown in Fig. 4B, following exposure of Wit A, TGF- $\beta$-treated Caski cells transfected with the empty vector exhibted a decrease in cell invasion, which was slightly blocked by ectopic expression of CA-Akt. For determination of whether the decrease in TGF- $\beta$-induced MMP-9 secretion by Wit A was related to the Akt signaling pathway, Caski cells were transiently transfected with an empty vector and CA-Akt expression vector. Treatment of TGF- $\beta$-treated Caski cells transfected with the empty vector led to a decrease in MMP-9 
A
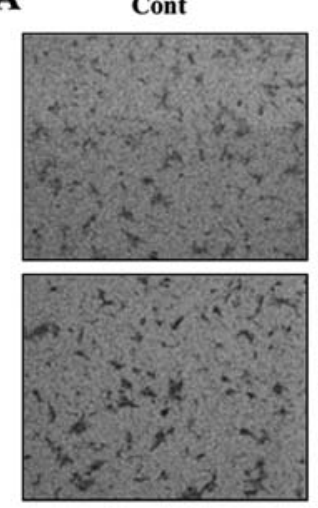

TGF- $\beta$

+ Wit $\mathbf{A}$
TGF- $\beta$
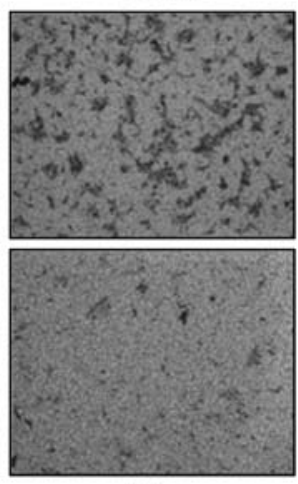

Wit A
B

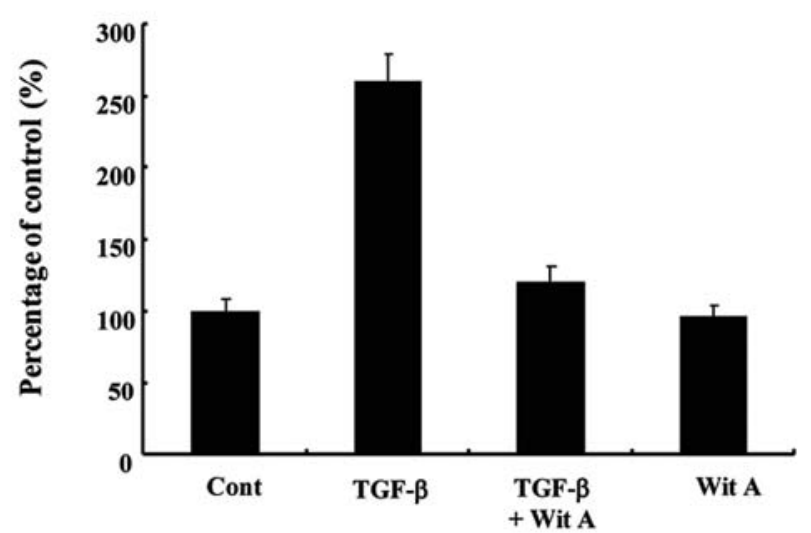

Figure 3. Effect of Wit A on Matrigel invasion in Caski cells. (A) For the invasion assay, the lower and upper parts of Transwells were coated with Matrigel. Caski cells cultured in the presence or absence of either TGF- $\beta$ or Wit A at the indicated concentrations were placed in the upper well. Invasiveness of the cells was determined by measurement of the ability to pass through a filter coated with a layer of Matrigel. After $24 \mathrm{~h}$, cells on the bottom side of the filter were fixed, stained, and counted as described in 'Materials and methods'. Representative images demonstrating cell invasion are shown. (B) Data represent the mean of at least three independent experiments. The bars represent the standard error of the values.

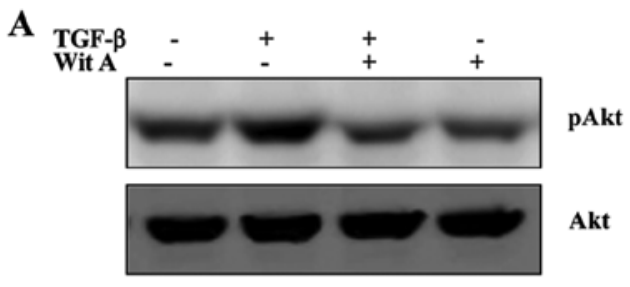

B

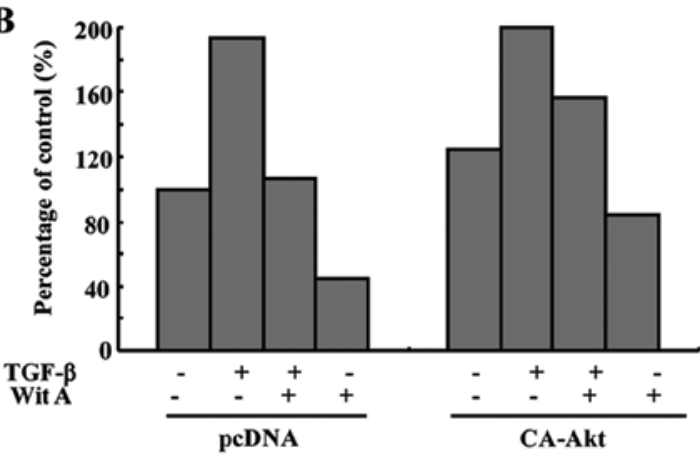

C
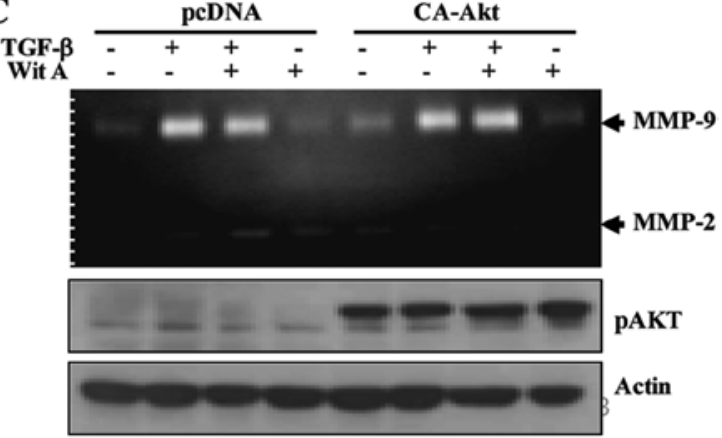

Figure 4. Wit A inhibits TGF- $\beta$-induced secretion of MMP-9 and phosphorylation of Akt in Caski cells. (A) Caski cells were treated with vehicle, TGF- $\beta$ $(50 \mathrm{ng} / \mathrm{ml})$, Wit A $(1.2 \mu \mathrm{M})$, and TGF- $\beta$ plus Wit A for $24 \mathrm{~h}$. Equal amounts of cell lysates $(40 \mu \mathrm{g})$ were subjected to electrophoresis and analyzed by immunoblotting using phosphorylation state-specific antibodies. To ascertain that the total level of Akt did not change, an independent blot was probed with the antibody raised against phosphorylation-independent Akt. (B) Ectopic expression of CA-Akt resulted in attenuated TGF- $\beta$-induced invasion in Caski cells. Caski cells were transiently transfected with CA-Akt expression vector and empty vector (pcDNA3.1) and treated with TGF- $\beta$ in the presence or absence of Wit A for $24 \mathrm{~h}$. Afterward, invasiveness of the cells was determined by measurement of the ability to pass through a filter coated with a layer of Matrigel. Each data value represents the mean of at least three independent experiments. The bars represent the standard error of the values. (C) Ectopic expression of CA-Akt resulted in attenuated TGF- $\beta$-induced MMP-9 secretion in Caski cells. Caski cells were transiently transfected with a CA-Akt expression vector and empty vector (pcDNA3.1) and treated with TGF- $\beta$ in the presence or absence of Wit A for $24 \mathrm{~h}$. The culture medium was subjected to gelatin and casein zymography for analysis of the activities of MMP-2 and MMP-9.

secretion, which was slightly blocked by ectopic expression of CA-Akt (Fig. 4C). This result indicated that the decrease in TGF- $\beta$-induced MMP-9 secretion by Wit A was related to inhibition of the Akt signaling pathway in Caski cells. Taken together, treatment with Wit A resulted in decreased inhibition of TGF- $\beta$-induced secretion of MMP- 9 and TGF- $\beta$-stimulated MMP-9 secretion via blockade of the Akt signaling pathway in Caski cells.
Effect of Wit A on MMP-9 activity and expression. Caski cells were treated with $75 \mathrm{nM}$ PMA for $24 \mathrm{~h}$. PMA induced expression and secretion of large amounts of latent MMP-9, as determined by gelatin zymography (Fig. 5A). As shown in Fig. 5A, treatment with Wit A resulted in a decrease in PMA-induced MMP-9 activity in a dose-dependent manner. Treatment of Caski cells with Wit A also induced a decrease in the levels of PMA-stimulated MMP-9 mRNA (Fig. 5B). 

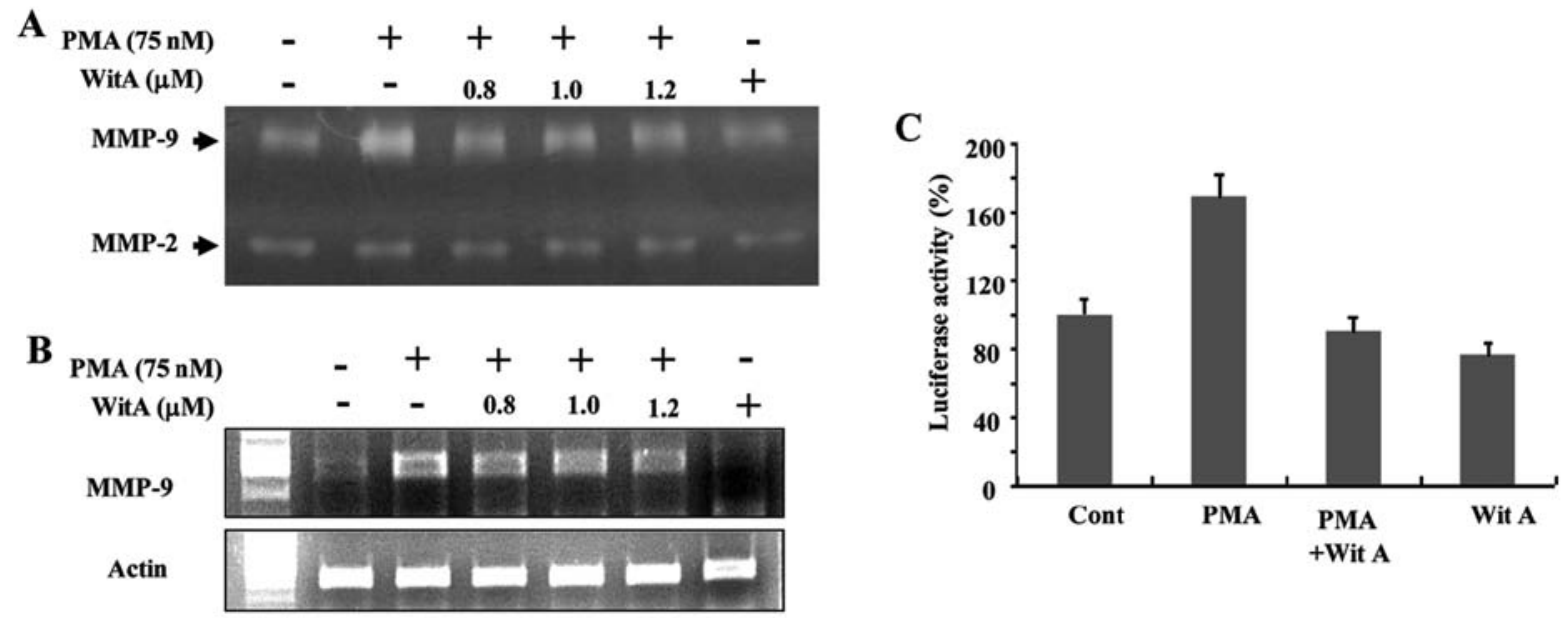

Figure 5. Wit A inhibits PMA-induced expression and activity of MMP-9 in Caski cells. (A) Caski cells were treated with various concentrations or without Wit A in the presence of PMA $(75 \mathrm{nM})$. The conditioned media were collected, and gelatin and casein zymography was performed for determination of MMP-2 and MMP-9 activities. (B) Caski cells were treated with various concentrations or without Wit A in the presence of PMA (75 nM). Total RNA was isolated, and RT-PCR analysis was performed. The MMP-9 mRNA levels shown are representative of three independent experiments. (C) Caski cells were transfected with the WT-MMP-9 promoter-containing reporter vector and treated with various concentrations of Wit A in the absence or presence of PMA (75 nM). The cells were lysed, and the luciferase activity was measured. Results are shown as means \pm SE. The bars represent the standard error of the values.
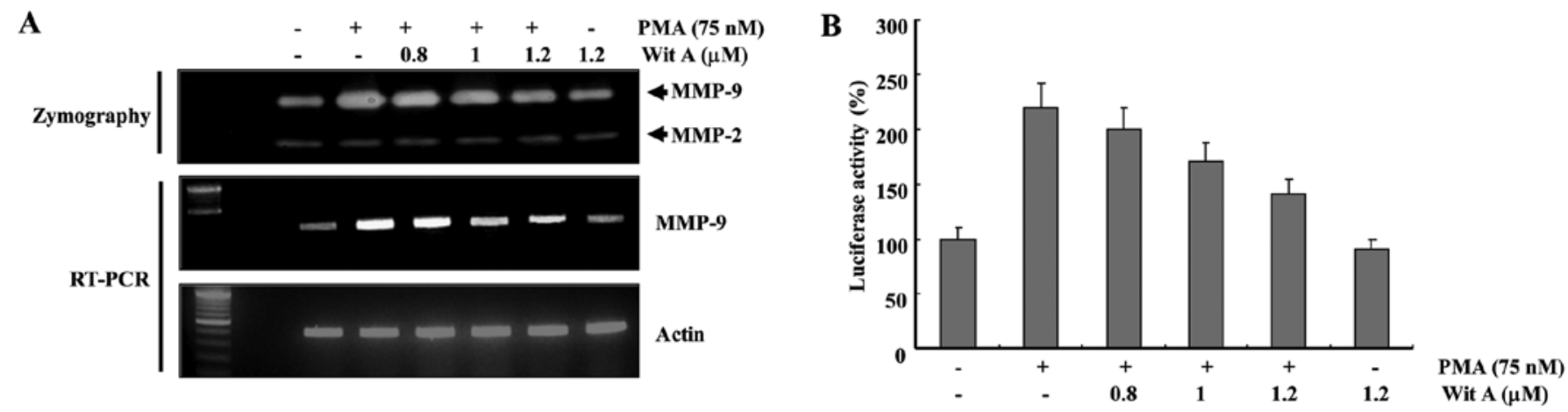

Figure 6. Wit A inhibits PMA-induced expression and activity of MMP-9 in SK-Hep1 cells. (A) SK-Hep-1 cells were treated with various concentrations or without Wit A in the presence of PMA $(75 \mathrm{nM})$ for $24 \mathrm{~h}$. The conditioned media were collected, and gelatin and casein zymography was performed for determination of MMP-2 and MMP-9 activities (top panel). Total RNA was isolated, and RT-PCR analysis was performed. The MMP-9 mRNA levels shown are representative of three independent experiments (bottom panel). (B) SK-Hep1 cells were transfected with the WT-MMP-9 promoter-containing reporter vector and treated with various concentrations of Wit $\mathrm{A}$ in the absence or presence of PMA $(75 \mathrm{nM})$. The cells were lysed, and the luciferase activity was measured. Results are shown as mean \pm SE. The bars represent the standard error of the values.

The effect of Wit A on MMP-9 expression was additionally investigated using Caski cells transiently transfected with an MMP-9 promoter plasmid. As shown in Fig. 5C, activation of luciferase gene expression up to 1.8 -fold was observed in cells treated with PMA, when compared with the untreated cells. Treatment of cells with Wit A $(1.2 \mu \mathrm{M})$ resulted in a decrease in PMA-mediated luciferase activity.

Wit A inhibits PMA-induced MMP-9 expression in a metastatic cancer cell line. We further attempted to determine whether Wit A attenuates PMA-induced MMP-9 expression and activity in another human metastatic cancer cell line, SK-Hep1. As shown in Fig. 6A, treatment with Wit A resulted in a decrease in PMA-induced MMP-9 activity in SK-Hep1 cells in a dose-dependent manner. In addition, treatment of SK-Hep1 cells with Wit A also induced a decrease in the levels of PMA-stimulated MMP-9 mRNA or luciferase activity in a dose-dependent manner (Fig. 6 and B).

\section{Discussion}

Tumor invasion and metastasis involve a complex multi-step process, and are the leading causes of death of cancer patients. Therefore, inhibition of invasion and metastasis by chemopreventive agents has been suggested as a potential therapeutic strategy for the treatment of cancers $(14,15)$. MMPs play a major role in the promotion of metastasis in cancer development. Currently, there are <20 known human MMPs; MMP-2 and -9 have been studied extensively due to their key roles in degradation of type IV collagen and gelatin, as well as the strong association between MMP-2 and -9 in human lung and cervical cancers $(16,17)$. Therefore, an efficient therapeutic molecule that efficiently inhibits expression or activity of MMP-9 could interfere with the invasiveness of cancer cells, and, thus, provide a therapeutic target against human metastatic cancer. 
The usefulness of low-molecular-weight Wit A for the prevention of tumor growth has been reported in many different types of human cancers (8-10). However, the precise actions of Wit $\mathrm{A}$ in invasion and migration of human cervical cancer cells and the associated signaling pathways have not been reported. In this study, we found that treatment with Wit A resulted in suppression of TGF- $\beta$-enhanced MMP- 9 secretion and mRNA expression, and invasiveness in cervical cancer cells.

Accumulating evidence has indicated close involvement of the Akt pathway in angiogenesis via activation of proliferation $(18,19)$. In addition, activation of MMP-9 can occur via PI3K-AKT signaling pathways in ovarian cancer cells (20). In the present study, we found that pre-treatment with Wit A resulted in markedly inhibited TGF- $\beta$-triggered activation of Akt in human cervical cancer cells. In addition, introduction with CA-Akt resulted in a partial increase in the secretion of TGF- $\beta$-induced MMP-9 attenuated by treatment of Caski cells with Wit A. These results indicate that treatment with Wit $\mathrm{A}$ resulted in inhibition of the invasive and migratory abilities of Caski cells by reducing MMP-9 expression via suppression of the Akt signaling pathway. Further extensive study of the role of Akt activation in TGF- $\beta$ induced MMP-9 expression is warranted.

We also demonstrated the inhibition of TGF- $\beta$-induced MMP-9 mRNA expression and its activity by treatment with Wit A in SK-Hepl cells, suggesting the possibility that Wit A may commonly regulate MMP-9 induction by TGF- $\beta$ at the transcriptional level in different types of cancer cells. In addition, treatment with Wit A also inhibited PMA-induced MMP-9 mRNA expression and its activity in Caski cells. Thus, these studies indicate MMP-9 as a potential target molecule for the anti-invasive and anti-migratory activities of Wit $\mathrm{A}$ in cancer cells.

In conclusion, we showed that Wit A inhibited TGF- $\beta$-induced invasion and metastasis through a reduction in expression and secretion of MMP-9 through the Akt pathway in Caski human cervical cancer cells. In addition, the inhibitory effect on MMP-9 induction by treatment with Wit A was also observed in human hepatoma SK-Hep1 cells. Overall, these findings demonstrate the potential of Wit A as a powerful candidate for use in the development of chemopreventive agents for cancer metastasis.

\section{Acknowledgements}

This research was supported by the Basic Science Research Program through the National Research Foundation of Korea (NRF) funded by the Korean government (MEST) (no. 2010-0011228) and by the National Research Foundation of Korea (NRF) grant funded by the Korean government (MEST) (2012-0000286).

\section{References}

1. Westermarck J and Kähäri VM: Regulation of matrix metalloproteinase expression in tumor invasion. FASEB J 13: 781-792, 1999.

2. Johansson N, Ahonen M and Kähäri VM: Matrix metalloproteinases in tumor invasion. Cell Mol Life Sci 57: 5-15, 2000.

3. Murphy $\mathrm{G}$ and Nagase H: Progress in matrix metalloproteinase research. Mol Aspects Med 29: 290-308, 2008.

4. Yu W, Liu J, Xiong X, Ai Y and Wang H: Expression of MMP9 and CD147 in invasive squamous cell carcinoma of the uterine cervix and their implication. Pathol Res Pract 205: 709-715, 2009.

5. Piao S, Zhao S, Guo F, et al: Increased expression of CD147 and MMP-9 is correlated with poor prognosis of salivary duct carcinoma. J Cancer Res Clin Oncol 138: 627-635, 2012.

6. Libra M, Scalisi A, Vella N, et al: Uterine cervical carcinoma: role of matrix metalloproteinases (Review). Int J Oncol 34: 897-903, 2009.

7. Sakata K, Shigemasa K, Nagai N and Ohama K: Expression of matrix metalloproteinases (MMP-2, MMP-9, MT1-MMP) and their inhibitors (TIMP-1, TIMP-2) in common epithelial tumors of the ovary. Int J Oncol 17: 673-681, 2000.

8. Srinivasan S, Ranga RS, Burikhanov R, Han SS and Chendil D: Par-4-dependent apoptosis by the dietary compound withaferin A in prostate cancer cells. Cancer Res 67: 246-253, 2007.

9. Hahm ER, Moura MB, Kelley EE, Van Houten B, Shiva S and Singh SV: Withaferin A-induced apoptosis in human breast cancer cells is mediated by reactive oxygen species. PLoS One 6: e23354, 2011.

10. Zhang X, Samadi AK, Roby KF, Timmermann B and Cohen MS: Inhibition of cell growth and induction of apoptosis in ovarian carcinoma cell lines $\mathrm{CaOV} 3$ and SKOV3 by natural withanolide Withaferin A. Gynecol Oncol 124: 606-612, 2012.

11. Mohan R, Hammers HJ, Bargagna-Mohan P, et al: Withaferin A is a potent inhibitor of angiogenesis. Angiogenesis 7: 115-122, 2004.

12. Lee J, Hahm ER and Singh SV: Withaferin A inhibits activation of signal transducer and activator of transcription 3 in human breast cancer cells. Carcinogenesis 31: 1991-1998, 2010.

13. Overall CM, Wrana JL and Sodek J: Independent regulation of collagenase, 72-kDa progelatinase, and metalloendoproteinase inhibitor expression in human fibroblasts by transforming growth factor-beta. J Biol Chem 264: 1860-1869, 1989.

14. Kohn EC and Liotta LA: Molecular insights into cancer invasion: strategies for prevention and intervention. Cancer Res 55: 1856-1862, 1995.

15. Sporn MB: The war on cancer. Lancet 347: 1377-1381, 1996.

16. Ylisirniö S, Höyhtyä M and Turpeenniemi-Hujanen T: Serum matrix metalloproteinases $-2,-9$ and tissue inhibitors of metalloproteinases $-1,-2$ in lung cancer - TIMP-1 as a prognostic marker. Anticancer Res 20: 1311-1316, 2000.

17. Li Y, Wu T, Zhang B, Yao Y and Yin G: Matrix metalloproteinase-9 is a prognostic marker for patients with cervical cancer. Med Oncol 29: 3394-3399, 2012.

18. Fang J, Ding M, Yang L, Liu LZ and Jiang BH: PI3K/PTEN/AKT signaling regulates prostate tumor angiogenesis. Cell Signal 19: 2487-2497, 2007.

19. Cai WJ, Wang MJ, Moore PK, Jin HM, Yao T and Zhu YC: The novel proangiogenic effect of hydrogen sulfide is dependent on Akt phosphorylation. Cardiovasc Res 76: 29-40, 2007.

20. Thant AA, Nawa A, Kikkawa F, et al: Fibronectin activates matrix metalloproteinase-9 secretion via the MEK1-MAPK and the PI3K-Akt pathways in ovarian cancer cells. Clin Exp Metastasis 18: 423-428, 2000. 